\title{
NEWS \\ One in three warnings issued by the GDC relate to a dentist's personal conduct
}

The results of a Freedom of Information (FOI) request to the General Dental Council (GDC) by Dental Protection demonstrate how important it is for dental professionals to have comprehensive indemnity cover and dento-legal support when faced with GDC proceedings.

Nearly one third (29\%) of the warnings issued by the GDC in the past five years relate to personal conduct matters. Three quarters of these were given as a result of a driving offence.

This data supports the importance for dentists to ensure they hmaintain their membership of a dental defence organisation that will safeguard their interests and reputation before the regulator.

Dental Protection regularly defends members on a wide range of matters - including personal conduct matters. However, not all organisations provide protection against GDC investigations that relate to personal conduct, and so the dentist would have to personally pay for this legal support when faced by the regulator. When choosing their indemnity provider, it is important for dentists to consider whether their indemnity in GDC cases is limited to 'the practice of dentistry'.
Having effective legal representation may also help a dentist to eliminate the risk of a warning altogether. In late 2018, Dental Protection brought Judicial Review proceedings against the GDC's decision to issue a warning to a member who had committed a minor driving offence. In this case, Dental Protection successfully argued that a warning would be an excessive and unjust sanction by the regulator.

The FOI request to the GDC also revealed that nearly three in $10(27 \%)$ warnings issued to dentists related to record keeping.

Raj Rattan, Dental Director at Dental Protection, said: 'The GDC investigation process can be very unsettling for dentists who fear that their reputation is at stake. If you receive a warning you will have to disclose details of the sanction in any future job applications. Any dentist who receives a published warning will also find that details of the warning are put on the GDC website.

'While many healthcare professionals may feel that personal conduct issues do not necessarily make you unfit to practise, the GDC are clear that dental professionals have a responsibility in their personal life to behave appropriately.'

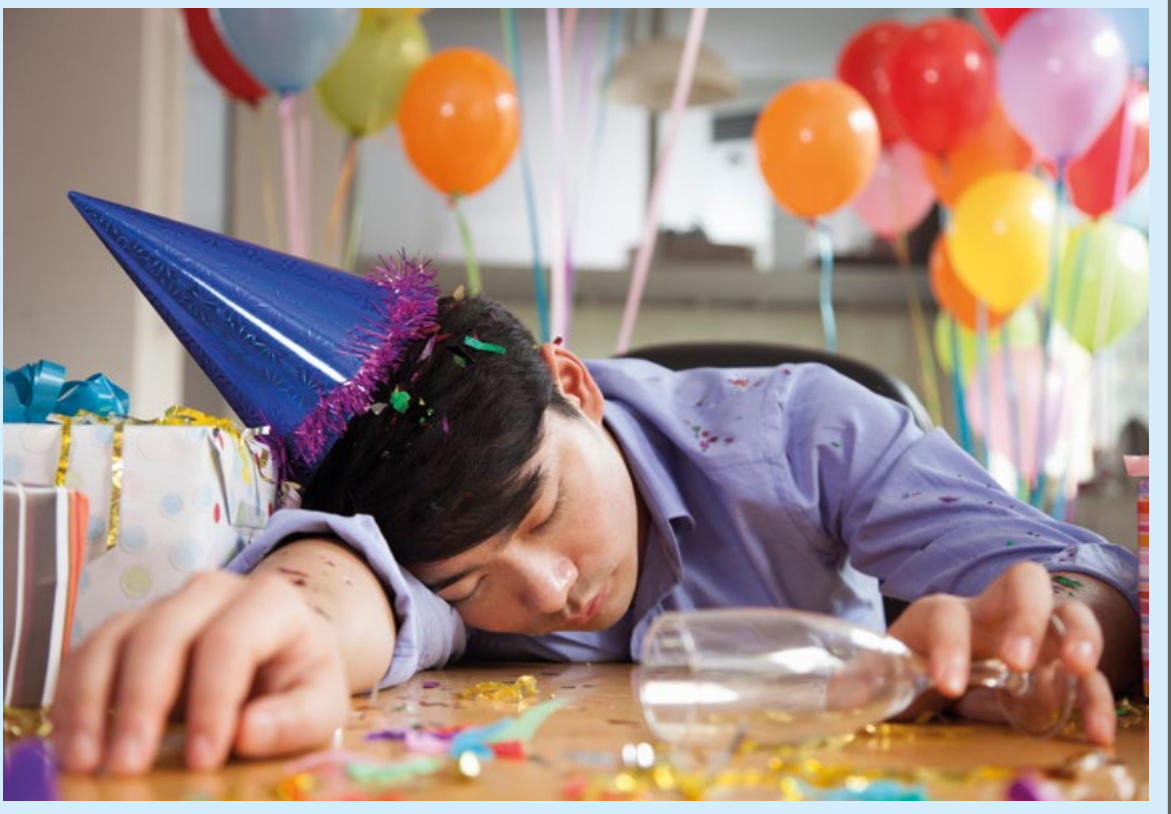

\section{NEWS}

DCbyl Practice of the Year

\section{Award nominations open}

CDO of England, Sara Hurley has announced the launch of the 2019 NASDAL

Dental Check by One Practice of the Year award.

The award seeks to

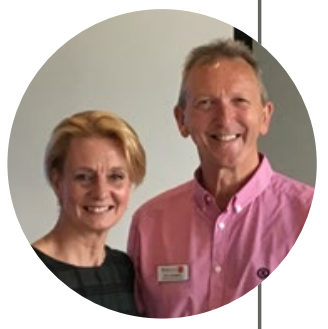

recognise a practice that has successfully introduced the British Society of Paediatric Dentistry (BSPD) Dental Check by One into their practice. The aim of the campaign is to increase the number of children who access dental care aged 0-2 years.

Sara Hurley added: 'I am delighted to endorse such a worthwhile award. The UK-wide Dental Check by One campaign was launched by BSPD in partnership with the Office of the Chief Dental Officer England (OCDO) and we are strong supporters of the initiative and early attendance. I look forward to hearing how the entrants have reached out to their communities and engaged with families.'

Nick Ledingham, Chairman of NASDAL, said: 'We know that doing the right thing makes good business sense - as an association we look to recognise business excellence in dentistry. This award recognises those practices whose efforts and imagination have reached more patients.

Liz Roebuck, President of BSPD, welcomed the formal announcement off the 2019 award saying: 'When DCby1 was first launched, we were convinced that it would be highly rewarding for the practices that committed to it. Our expectations were exceeded with the entries for the 2018 NASDAL DCbyl Practice of the Year Award. We are delighted to continue our support for award. and look forward to reading more inspiring entries in 2019.'

Practices who are interested in entering the 2019 NASDAL DCbyl award, should visit https://www.nasdal.org.uk/award/ index.php where they will find all the relevant details and register. All entries must be submitted before $5 \mathrm{pm}$, Friday 30 August 2019. 